\title{
IMPLEMENTASI DATA MINING UNTUK PENGELOMPOKKAN DAN PREDIKSI KARYAWAN YANG BERPOTENSI PHK DENGAN ALGORITMA K-MEANS CLUSTERING
}

\author{
Windania Purba, Willy Siawin, Hardih, Marlince Nababan, N P Dharshinni, Siti Aisyah \\ Universitas Prima Indonesia \\ Jalan sekip Jalan Sikambing No. Simpang, Sei Putih Tim. I, Medan Petisah, Kota Medan, Sumatera Utara 20111 \\ E-mail :Winda.nia04@gmail.com willysiawin@yahoo.co.id, wijayahardi97@gmail.com
}

\begin{abstract}
ABSTRAK- Penelitian ini dilakukan untuk mempelajari Data Mining dengan menggunakan algoritma $K$ MeanClustering yang diimplementasikan dalam perusahaan PT. Berlian Transtar Abadi untuk mengelompokkan dan melakukan prediksi terhadap karyawan yang berpotensi PHK. Data dikumpulkan dengan cara wawancara dan observasi terhadap pihak yang bersangkutan, selanjutnya data dianalisa untuk menentukan karyawan yang berpotensi PHK. Dari eksperimen yang dilakukan dengan menggunakanalgoritma $K$-means serta menggunakan software Visual Basic V10 dapat memberikan hasil yang akurat.
\end{abstract}

Kata kunci:Data Mining, K-Mean Clustering, Karyawan.

\section{PENDAHULUAN}

Seiring dengan berkembangnya kemajuan ilmu pengetahuan dan teknologi, jumlah permintaan sumberdaya komputer juga semakin meningkat. Beberapa bidang yang membutuhkan komputasi tingkat tinggi adalah simulasi numerik, masalahmasalah teknis seperti rendering gambar yang membutuhkan waktu proses yang singkat.

Pengambilan keputusan berusaha untuk memanfaatkan gudang data yang sudah dimiliki untuk menggali informasi yang berguna membantu mengambil kesimpulan, hal ini menjadikan munculnya cabang ilmu baru untuk mengatasi masalah penggalian informasi atau pola yang penting atau menarik dari data dalam jumlah yang besar, yang disebut dengan Data Mining. Penggunaan teknik Data Mining diharapkan dapat memberikan pengetahuanpengetahuan yang sebelumnya. (Susanto, dkk, 2015).

PT. Berlian Transtar Abadi adalah salah satu perusahaan yang bergerak di bidang PPJK (Custom clearance Export-Import di Medan, Jakarta dan Surabaya), EMKL dan Trucking. Perusahaan dalam setiap tahunnya melakukan penilaian atas kinerja karyawan sehingga dapat diketahui karyawan yang berprestasi maupun karyawan yang memiliki kinerja sangat rendah atau di luar harapan perusahaan. Hasil penilaian ini juga digunakan sebagai dasar pengambilan keputusan bagi manajemen perusahaan dalam melakukan Pemutusan Hubungan Kerja (PHK). PHK dilakukan setelah perusahaan melakukan penilaian berdasarkan absensi, kinerja, pemahaman, attitude dan cara berkomunikasi. Hal ini dilakukan agar karyawan perusahaan terus berusaha agar memiliki produktivitas kerja yang tinggi serta memiliki loyalitas kerja yang tinggi terhadap perusahaan. Pelaksanaan klasifikasi karyawan yang digunakan sebagai dasar pemutusan hubungan kerja yang diterapkan perusahaan masih menggunakan sistem manual sehingga menghasilkan informasi tidak akurat serta sering mendapat komplain dari karyawan, maka diperlukan sistem baru berbasis komputerisasi.

Aplikasi Data Mining untuk pengelompokkan dan prediksi karyawan yang berpotensi PHK dirancang menggunakan metode K-Means Clustering. Metode ini membantu pihak manajemen dalam melakukan pengelompokkan karyawan sehngga dapat di prediksi karyawan yang memiliki potensi kena PHK dari beberapa kriteria yang telah ditentukan sehingga hasil penilaiannya lebih obyektif dan akurat. Tujuan Tujuan penelitian ini adalah sebagai berikut :

1.Untuk mengetahui proses kerja Data Mining untuk pengelompokkan dan prediksi karyawan yang berpotensi PHK pada PT. Berlian Transtar Abadi Medan.

2.Untuk merancang Data Mining untuk pengelompokkan dan prediksi karyawan yang berpotensi PHK dengan algoritma K-Means Clustering pada PT. Berlian Transtar Abadi Medan.

3.Untuk mengimplementasikan Data Mining untuk pengelompokkan dan prediksi karyawan yang berpotensi PHK dengan algoritma K-Means Clustering pada PT. Berlian Transtar Abadi Medan.

\section{ISI PENELITIAN Pengertian Data Mining}

Data Mining adalah penggunaan otomatis teknik analisis data

untuk mengungkap hubungan yang sebelumnya tidak terdeteksi antara data yang

item. Data Mining adalah proses untuk menemukan data yang sama dari database / data set di daerah yang berbeda seperti keuangan, industri ritel, ilmu pengetahuan, statistik, ilmu kedokteran, kecerdasan buatan, ilmu 
saraf. Ukuran data yang meningkat sangat cepat, sehingga, teknologi baru dan berkecepatan tinggi dan algoritma yang diperlukan untuk mengumpulkan dan memproses data ( Yadava et al, 2012) .

Data Mining merupakan proses iteratif dan interatif untuk menemukan pola atau model yang baru yang sahih (sempurna), bermanfaat dan dapat dimengerti dalam suatu database yang sangat besar (massive databases). Gambar berikut merupakan Tahap tahap menggali pengetahuan dari pangkalan data (Lindawati,2008)

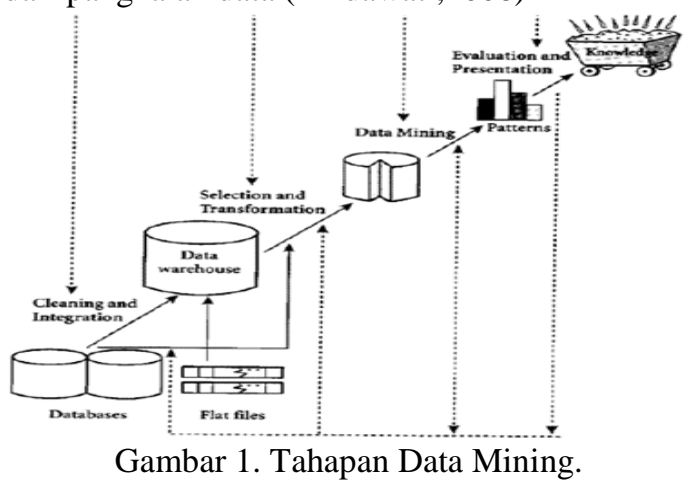

Tahap tahap Data Mining yang di ilustrasikan pada gambar dapat dijelaskan sebagai berikut:

1.Pembersihan data (untuk membuang data yang tidak konsisten dan noise)

2.Integrasi data (penggabungan data dari berbagai sumber)

3.Transformasi data(data diubah menjadi bentuk yang sesuai dengan teknik Data Mining)

4.Aplikasi teknik Data Mining

5.Evaluasi pola yang ditemukan (untuk menemukan informasi dan pengetahuan yang menarik)

6.Presentasi pengetahuan (dengan menggunakan teknik visualisasi)

Berdasarkan beberapa pengertian tersebut dapat ditarik kesimpulan bahwa Data Mining adalah suatu teknik menggali informasi berharga yang terpendam atau tersembunyi pada suatu koleksi data (database) yang sangat besar sehingga ditemukan suatu pola yang menarik yang sebelumnya tidak diketahui. Data Mining sendiri berarti usaha untuk mendapatkan sedikit barang berharga dari sejumlah besar material dasar. Karena itu Data Miningsebenarnya memiliki akar yang panjang dari bidang ilmu seperti kecerdasan buatan (artificial intelligent) machine learning, statistik dan database.

Data Mining adalah bagaimana menelusuri data yang ada untuk membangun sebuah model, Kemudian menggunakan model tersebut agar dapat mengenali pola data yang lain yang tidak berada dalam basis data yang tersimpan. Kebutuhan untuk prediksi juga dapat memanfaatkan teknik ini .Dalam Data Mining, pengelompokan data juga bisa dilakukan. Tujuanya adalah agar kita dapat mengetahui pola universal data -data yang ada. Anomali transaksi juga perlu dideteksi untuk dapat mengetahui tindak lanjutnya berikutnya yang dapat diambil. Semual hal tersebut bertujuan untuk mendukung kegiatan operasional perusahaan sehingga tujuan akhir perusahaan diharapkan dapat tercapai (Eko Prasetyo, 2012).

Data Mining memiliki pengertian lain yaitu knowledge discovery ataupun pattern recognition merupakan suatu bistilah yang digunakan untuk mendapatkan pengetahuan yang tersembunyi dari kumpulan data yang berukuran sangat besar. Tujuan utama data mining adalah untuk menemukan, menggali, atau menambang pengetahuan dari data atau informasi yang kita miliki (Susanto, 2010:2) Data mining merupakan bidang dari beberapa bidang keilmuan yang menyatukan teknik dari pembelajaran mesin, pengenalan pola, statistik, database, dan visualisasi untuk pengenalan permasalahan pengambilan informasi dari database yang besar (Larose, 2005). Data Mining adalah proses yang menggunakan teknik statistik, matematika, kecerdasan buatan, dan machine learning untuk mengekstraksi dan mengidentifikasi informasi yang bermanfaat dan pengetahuan yang terkait dari database yang besar.

\section{K Means Clustering}

Menurut Tutik (2014) K-Means adalah salah satu algoritma yang menggunakan metode partisi.KMeans adalah algoritma clustering yang membagi masing-masing item data ke dalam satu cluster.

K-Means adalah suatu teknik pengelompokkan data yang mana keberadaan tiap-tiap titik data dalam suatu cluster ditentukan oleh derajat keanggotaan. Teknik ini pertama kali diperkenalkan oleh Jim Bezdek pada tahun 1981 (Deka Dwinavinta et al, 2014).

Menurut Johan (2013) K-means clustering merupakan salah satu metode data clustering nonhirarki yang mengelompokkan data dalam bentuk satu atau lebih cluster/kelompok. Data-data yang memiliki karakteristik yang sama dikelompokkan dalam satu cluster/kelompok dan data yang memiliki karakteristik yang berbeda dikelompokkan dengan cluster/kelompok yang lain sehingga data yang berada dalam satu cluster/kelompok memiliki tingkat variasi yang kecil.

K-Means merupakan salah satu metode pengelompokan data nonhierarki (sekatan) yang berusaha mempartisi data yang ada ke dalam bentuk dua atau lebih kelompok. Adapun tujuan pengelompokkan data ini adalah untuk meminimalkan fungsi objektif yang diatur dalam proses pengelompokan, yang pada umumnya 
berusaha meminimalkan variasi di dalam suatu kelompok dan memaksimalkan variasi antar kelompok (Afrisawati, 2013).

Dari beberapa definisi di atas dapat disimpulkan bahwa K-Means Clustering adalah metode pengelompokan yang mempartisi data kedalam kelompok yang memiliki karakteristik sama dimasukkan ke dalam kelompok yang sama di mana set data yang dimasukkan ke dalam kelompok tidak tumpang tindih.

\section{Langkah - langkah Melakukan K- Means Clustering}

Menurut Ni Ketut (2014), tahapan melakukan clustering atau pengelompokan dengan metode KMeans adalah sebagai berikut :

1.Menentukan berapa banyak cluster yang ingin yang ingin dibentuk, di mana nilai $\mathrm{K}$ adalah banyaknya cluster/ jumlah cluster.

2.Menentukan pusat cluster (centroid) awal. Centroid awal ditentukan secara acak dari data yang ada dan jumlah centroid awal sama dengan jumlah cluster.

3.Setelah menentukan centroid awal, maka setiap data akan menemukan centroid terdekatnya yaitu dengan menghitung jarak setiap data ke masingmasing centroid menggunakan rumus korelasi antar dua obyek yaitu Euclidean Distance.

4.Setelah menghitung jarak data ke centroidnya, maka langkah berikutnya adalah mengelompokan data berdasarkan jarak minimumnya. Suatu data akan menjadi anggota dari suatu cluster yang memiliki jarak terdekat (terkecil) dari pusat cluster-nya.

5.Berdasarkan pengelompokan tersebut, selanjutnya adalah mencari centroid baru berdasarkan membership dari masing-masing cluster yaitu dengan menghitung rata-rata dari data masing-masing cluster.

6.Kembali ke tahap 3.

7.Perulangan berhenti apabila tidak ada data yang berpindah.

Menurut Tutik (2014) untuk menentukan nilai pusat (centroid) pada tahap iterasi digunakan rumus sebagai berikut :

$v_{i j}=\frac{1}{N_{i}}=\sum_{k=0}^{N_{i}} x_{k i}$

Di mana :

$\mathrm{Vij}=\quad$ centroid rata-rata cluster ke-i untuk variable $\mathrm{k}-\mathrm{j}$

$\mathrm{Ni}=$ jumlah anggota cluster ke-i

$\mathrm{i}, \mathrm{k}=$ indeks dari cluster

$\mathrm{j}=$ indeks dari variable

$\mathrm{Xkj}=\quad$ nilai data $\mathrm{ke}-\mathrm{k}$ variable $\mathrm{ke}-\mathrm{j}$ dalam cluster tersebut.

Menurut Afrisawati (2013) untuk menentukan korelasi antar dua obyek yaitu dengan menggunakan rumus Euclidean Distance berikut:

$$
d_{\text {Euclidean }}(x, y)=\sqrt{\sum_{i=1}^{n}\left(x_{i}-y_{i}\right)^{2}}
$$

Di mana :

$d(x, y)=$ jarak data ke $x$ ke pusat cluster $y$

$x_{\tilde{i}} \quad=$ data ke- $i$ pada atribut data ke $n$

$y_{i} \quad=$ data ke-j pada atribut data ke $n$

Demikianlah rumus yang digunakan untuk menentukan korelasi antara dua objek yaitu dengan menggunakan rumus Eucldean Distance.

\section{Metode Penelitian}

Metode penelitian yang digunakan dalam penelitian ini termasuk ke dalam penelitian yang bersifat deskriptif. Penelitian deskriptif adalah penelitian yang bertujuan untuk memperoleh ciriciri variabel, di mana dalam penelitian ini adalah untuk memperoleh gambaran tentang kinerja program yang dirancang dan diimplementasikan kepada pengguna (user) dengan pendekatan studi kasus pada karyawan perusahaan.

\section{Subjek Penelitian}

Subjek yang digunakan dalam penelitian ini adalah implementasi data mining untuk pengelompokkan dan klasifikasi karyawan yang berpotensi PHK menggunakan algoritma KMeans Clustering.

\section{Metode Pengumpulan Data}

Metode pengumpulan data yang digunakan dalam penelitian ini adalah sebagai berikut :

a.Studi pustaka

Studi Pustaka dilakukan untuk memperoleh data sebagai bahan acuan yang akan digunakan dalam implementasi aplikasi yang dibuat, baik dari buku, jurnal, maupun bahan referensi lainnya yang memiliki relevansi dengan penelitian yang dilakukan, seperti pengertian data mining, maupun algoritma K_Means Clustering.

\section{a.Wawancara}

Wawancara merupakan metode pengumpulan data dengan mengajukan pertanyaan-pertanyaan tentang sistem yang sedang berjalan dengan segala kekurangan sebagai kajian dalam pembuatan program aplikasi yang akan diajukan sebagai sistem yang baru.

\section{b.Observasi}

Metode ini merupakan pengamatan langsung yang dapat mempermudah dalam proses pengumpulan data, sehingga data-data yang di dapat terjamin keaslian dan kebenarannya. Pengamatan langsung dilakukan pada bagian personalia perusahaan dengan mengadakan pencatatan terhadap 
dokumen-dokumen yang ada serta berkaitan dengan pengelompokkan dan klasifikasi karyawan yang berpotensi PHK.

\section{Analisis Sistem}

Analisa sistem digunakan untuk melakukan analisis permasalahan sistem yang akan dibuat mencakup data yang dibutuhkan serta pendeskripsian data sehingga dapat diperoleh proses kerja sistem yang akan dikembangkan secara manual, serta kelebihan dan kelemahannya agar dapat diajukan sebagai dasar pembuatan sistem yang baru.

\section{Perancangan sistem}

Dilakukan untuk merancang sistem yang baru mencakup proses kerja sistem yang baru, perancangan antar muka program dan perancangan database menggunakan unified modeling language.

\section{Implementasi}

Implementasi sistem digunakan untuk mengimplementasikan aplikasi yang dibuat ke dalam bahasa pemograman yang digunakan yaitu Visual Studio 2010 sehingga bisa menjadi sebuah sistem baru yang sesuai dengan tujuan penelitian.

\section{Pengujian Sistem}

Pengujian sistem dilakukan untuk menguji sistem yang dibuat sehingga dapat diketahui bahwa sistem sudah dapat bekerja sesuai yang diharapkan serta tidak ada lagi debug program. Pengujian sistem dilakukan dengan menggunakan metode black boxtest.

\section{Analisa Data}

Analisa terhadap data karyawan yang berpotensi kena PHK pada perusahaan dengan tujuan untuk mengelompokkan data dengan menggunakan metode K-Means Clustering. Adapun pengelompokan-pengelompokan tersebut digunakan langkah-langkah sebagai berikut :

\section{Sumber Data}

Sumber data pada penelitian ini di dapat dari PT. Berlian Transtar Abadi adalah contoh data penilaian karyawan yang dapat dijadikan sampel untuk analisa dan juga pengujian yang dapat dilihat pada Tabel 1 .

Tabel 1. Contoh Data Penilaian Karyawan.

\begin{tabular}{|c|l|l|l|l|l|l|}
\hline $\begin{array}{l}\text { N } \\
\mathbf{0}\end{array}$ & $\begin{array}{l}\text { Na } \\
\text { ma }\end{array}$ & $\begin{array}{l}\text { Absen } \\
\text { si }\end{array}$ & $\begin{array}{l}\text { Kine } \\
\text { rja }\end{array}$ & $\begin{array}{l}\text { Pema } \\
\text { hama } \\
\text { nattitu }\end{array}$ & $\begin{array}{l}\text { Kom } \\
\text { de } \\
\text { unik } \\
\text { asi }\end{array}$ \\
\hline $\begin{array}{l}\text { Bu } \\
\text { di }\end{array}$ & Baik & Baik & $\begin{array}{l}\text { Sangat } \\
\text { Baik }\end{array}$ & Baik & $\begin{array}{l}\text { Cuku } \\
\text { p }\end{array}$ \\
\hline $\begin{array}{l}\text { Iwa } \\
\mathrm{n}\end{array}$ & Baik & $\begin{array}{l}\text { Cuku } \\
\text { p }\end{array}$ & Cukup & Baik & $\begin{array}{l}\text { Cuku } \\
\text { puk }\end{array}$ \\
\hline
\end{tabular}

\begin{tabular}{|c|l|l|l|l|l|l|}
\hline 3 & $\begin{array}{l}\text { Wa } \\
\text { ti }\end{array}$ & $\begin{array}{l}\text { Renda } \\
\text { h }\end{array}$ & $\begin{array}{l}\text { Rend } \\
\text { ah }\end{array}$ & Baik & $\begin{array}{l}\text { Renda } \\
\text { h }\end{array}$ & $\begin{array}{l}\text { Cuku } \\
\text { p }\end{array}$ \\
\hline 4 & $\begin{array}{l}\text { Kel } \\
\text { vin }\end{array}$ & Cukup & Baik & Baik & Cukup & $\begin{array}{l}\text { Sang } \\
\text { at } \\
\text { Baik }\end{array}$ \\
\hline 5 & $\begin{array}{l}\text { Ton } \\
\text { i }\end{array}$ & $\begin{array}{l}\text { Sangat } \\
\text { Baik }\end{array}$ & Baik & $\begin{array}{l}\text { Renda } \\
\text { h }\end{array}$ & Baik & $\begin{array}{l}\text { Rend } \\
\text { ah }\end{array}$ \\
\hline 6 & $\begin{array}{l}\text { San } \\
\text { i }\end{array}$ & Cukup & $\begin{array}{l}\text { Cuku } \\
\text { p }\end{array}$ & Baik & $\begin{array}{l}\text { Sangat } \\
\text { Baik }\end{array}$ & Baik \\
\hline
\end{tabular}

Dari data mentah yang didapat diatas, peneliti menggunakan beberapa atribut yang dibutuhkan sebagai dasar untuk melakukan proses Clustering seperti absensi, kinerja, pemahaman, attitude dan cara komunikasi

\section{Tranformasi Data}

Pada tahap ini dilakukan proses perubahan data, tujuannya adalah agar data dapat diolah dengan menggunakan algoritma K-Means Clustering dan algoritma ini hanya bisa diolah dengan angka. Variabel yang dipilih pada data karyawan adalah absensi, kinerja, pemahaman, attitude dan cara komunikasi, baru kemudian di ubah ke dalam bentuk angka karena pada data tersebut belum berbentuk angka.

Tabel 2. Proses Perubahan Data Kebentuk Variabel

\begin{tabular}{|l|l|l|}
\hline No & Kriteria Penilaian & Kode \\
\hline 1 & Sangat Baik & 5 \\
\hline 2 & Baik & 4 \\
\hline 3 & Cukup & 3 \\
\hline 4 & Rendah & 2 \\
\hline 5 & Sangat Rendah & 1 \\
\hline
\end{tabular}

Tabel 3. Tabel Karyawan Setelah Transformasi

\begin{tabular}{|l|l|l|l|l|l|l|}
\hline $\begin{array}{l}\text { N } \\
\mathbf{o}\end{array}$ & $\begin{array}{l}\text { Na } \\
\text { ma }\end{array}$ & $\begin{array}{l}\text { Absen } \\
\text { si }\end{array}$ & $\begin{array}{l}\text { Kine } \\
\text { rja }\end{array}$ & $\begin{array}{l}\text { Pema } \\
\text { hama } \\
\mathbf{n}\end{array}$ & $\begin{array}{l}\text { Attit } \\
\text { ude }\end{array}$ & $\begin{array}{l}\text { Ko } \\
\mathbf{m u} \\
\text { nik } \\
\text { asi }\end{array}$ \\
\hline 1 & Budi & 4 & 4 & 5 & 4 & 3 \\
\hline 2 & Iwan & 4 & 3 & 3 & 4 & 3 \\
\hline 3 & Wati & 2 & 2 & 4 & 3 & 3 \\
\hline 4 & $\begin{array}{l}\text { Kelv } \\
\text { in }\end{array}$ & 3 & 4 & 4 & 3 & 5 \\
\hline 5 & Toni & 5 & 4 & 2 & 4 & 2 \\
\hline 6 & Sani & 3 & 3 & 4 & 5 & 4 \\
\hline
\end{tabular}

\section{Analisa Penerapan K-Means Clustering}

Setelah proses transformasi langkah selanjutnya adalah proses pengolahan data dengan menerapkan algoritma $K$-Means Clustering. Tahapan proses algoritma K-Means Clustering sudah dijelaskan pada tinjauan pustaka.

Langkah pertama yang harus dilakukan adalah menetukan jumlah cluster yang ingin dibentuk. Dalam penelitian ini cluster yang akan dibentuk adalah sebanyak 2 cluster. Kemudian tentukan titik 
JUSIKOM PRIMA (Junal Sistem Informasi Ilmu Komputer Prima)

Vol. 2 No. 1, Juli 2018

pusat awal dari setiap cluster. Dalam penelitian ini titik pusat awal ditentukan secara random dan di dapat titik pusat dari setiap cluster berdasarkan data adalah sebagai berikut :

Tabel 4. Titik Pusat Awal Cluster

\begin{tabular}{|l|l|l|l|l|}
\hline Cluster & Absensi & Kinerja & Pemahaman & Attitude \\
\hline $\begin{array}{l}\text { Cluster } \\
1\end{array}$ & 4 & 4 & 3 & 3 \\
\hline $\begin{array}{l}\text { Cluster } \\
2\end{array}$ & 2 & 2 & 3 & 3 \\
\hline
\end{tabular}

Perhitungan terus dilakukan hingga data terakhir dan jarak semua data sudah dihitung ke setiap pusat cluster. Hasil perhitungan seteiap data pada interasi I adalah sebagai berikut :

Tabel 5. Hasil perhitungan seteiap data pada interasi

\begin{tabular}{|c|c|c|c|c|c|c|c|c|}
\hline $\begin{array}{l}\mathbf{N} \\
\mathbf{o}\end{array}$ & $\begin{array}{l}\mathrm{Na} \\
\mathrm{ma}\end{array}$ & $\begin{array}{l}\text { Abs } \\
\text { ensi }\end{array}$ & $\begin{array}{l}\text { Kin } \\
\text { erj } \\
\text { a }\end{array}$ & $\begin{array}{l}\text { Pema } \\
\text { hama } \\
\text { n }\end{array}$ & $\begin{array}{l}\text { Atti } \\
\text { tud } \\
e\end{array}$ & $\begin{array}{l}\text { Kom } \\
\text { unik } \\
\text { asi }\end{array}$ & $\begin{array}{l}\mathrm{C} \\
1\end{array}$ & $\begin{array}{l}0 \\
2\end{array}$ \\
\hline 1 & $\begin{array}{l}\text { Bud } \\
\text { i }\end{array}$ & 4 & 4 & 5 & 4 & 3 & 2 & 4 \\
\hline 2 & $\begin{array}{l}\text { Iwa } \\
\mathrm{n}\end{array}$ & 4 & 3 & 3 & 4 & 3 & 1 & 2 \\
\hline 3 & $\begin{array}{l}\text { Wat } \\
\text { i }\end{array}$ & 2 & 2 & 4 & 3 & 3 & 3 & 1 \\
\hline 4 & $\begin{array}{l}\text { Kel } \\
\text { vin }\end{array}$ & 3 & 4 & 4 & 3 & 5 & 2 & 3 \\
\hline 5 & $\begin{array}{l}\text { Ton } \\
\mathrm{i}\end{array}$ & 5 & 4 & 2 & 4 & 2 & 2 & 4 \\
\hline 6 & Sani & 3 & 3 & 4 & 5 & 4 & 3 & 3 \\
\hline
\end{tabular}

Tabel 6. Anggota Setiap Cluster Iterasi I

\begin{tabular}{|l|l|}
\hline $\begin{array}{l}\text { Nama } \\
\text { Cluster }\end{array}$ & Anggota Cluster \\
\hline Cluster 1 & 1,2 \\
\hline Cluster 2 & 3,4 \\
\hline
\end{tabular}

Tabel 7. Hasil Perhitungan Setiap Data Pada Iterasi

\begin{tabular}{|l|l|l|l|l|l|l|l|l|}
\hline $\begin{array}{l}\text { N } \\
\mathbf{0}\end{array}$ & $\begin{array}{l}\text { Na } \\
\text { ma }\end{array}$ & $\begin{array}{l}\text { Abs } \\
\text { ensi }\end{array}$ & $\begin{array}{l}\text { Ki } \\
\text { ner } \\
\text { ja }\end{array}$ & $\begin{array}{l}\text { Pema } \\
\text { hama } \\
\text { n }\end{array}$ & $\begin{array}{l}\text { Atti } \\
\text { tud } \\
\text { e }\end{array}$ & $\begin{array}{l}\text { Kom } \\
\text { unik } \\
\text { asi }\end{array}$ & $\begin{array}{l}\text { C } \\
\mathbf{1}\end{array}$ & $\begin{array}{l}\text { C } \\
\mathbf{2}\end{array}$ \\
\hline 1 & $\begin{array}{l}\text { Bu } \\
\text { di }\end{array}$ & 4 & 4 & 5 & 4 & 3 & 1 & 3 \\
\hline 2 & $\begin{array}{l}\text { Iw } \\
\text { an }\end{array}$ & 4 & 3 & 3 & 4 & 3 & 1 & 2 \\
\hline 3 & $\begin{array}{l}\text { W } \\
\text { ati }\end{array}$ & 2 & 2 & 4 & 3 & 3 & 3 & 2 \\
\hline 4 & $\begin{array}{l}\text { Ke } \\
\text { lvi } \\
\text { n }\end{array}$ & 3 & 4 & 4 & 3 & 5 & 3 & 1 \\
\hline 5 & $\begin{array}{l}\text { To } \\
\text { ni }\end{array}$ & 5 & 4 & 2 & 4 & 2 & 3 & 4 \\
\hline 6 & $\begin{array}{l}\text { Sa } \\
\text { ni }\end{array}$ & 3 & 3 & 4 & 5 & 4 & 2 & 2 \\
\hline
\end{tabular}

\section{Tampilan Output Perangkat Lunak}

Untuk menjalankan aplikasi penerapan Data Mining Menggunakan Metode Clustering Studi Kasus PT. Berlian Transtar Abadi, maka pemakai ddparanengakses file 'Clustering.exe' yang terdapat

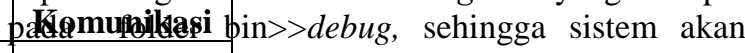
mȩnampilkan form login seperti terlihat pada gambar berikut:

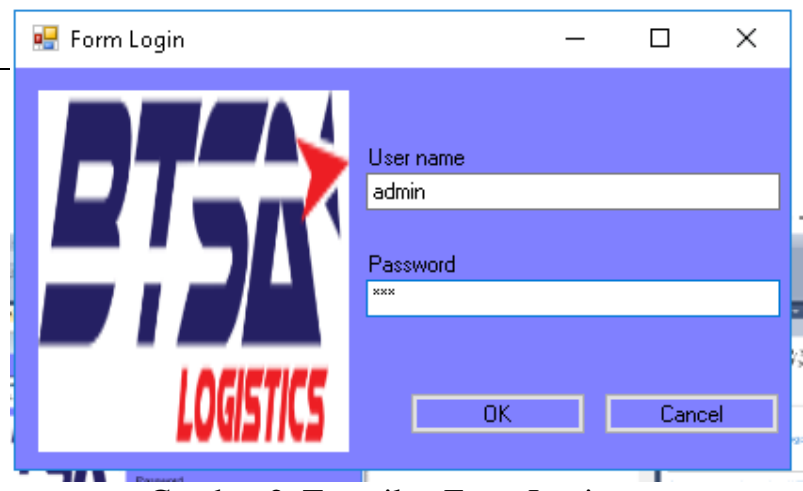

Gambar 2. Tampilan Form Login

Form login merupakan form awal yang akan muncul pada saat menjalankan perangkat lunak. Pada form ini harus di isi nama user dengan kata sandi dari pemakai terdaftar yang dapat menggunakan perangkat lunak. Apabila data pemakai yang dimasukkan valid, maka sistem akan menampilan form main. Pada form main ini terdapat menu yang digunakan sebagai penghubung (link) ke form-form lainnya yang terdapat pada perangkat lunak. Tampilan form 'Main' dapat dilihat pada gambar :

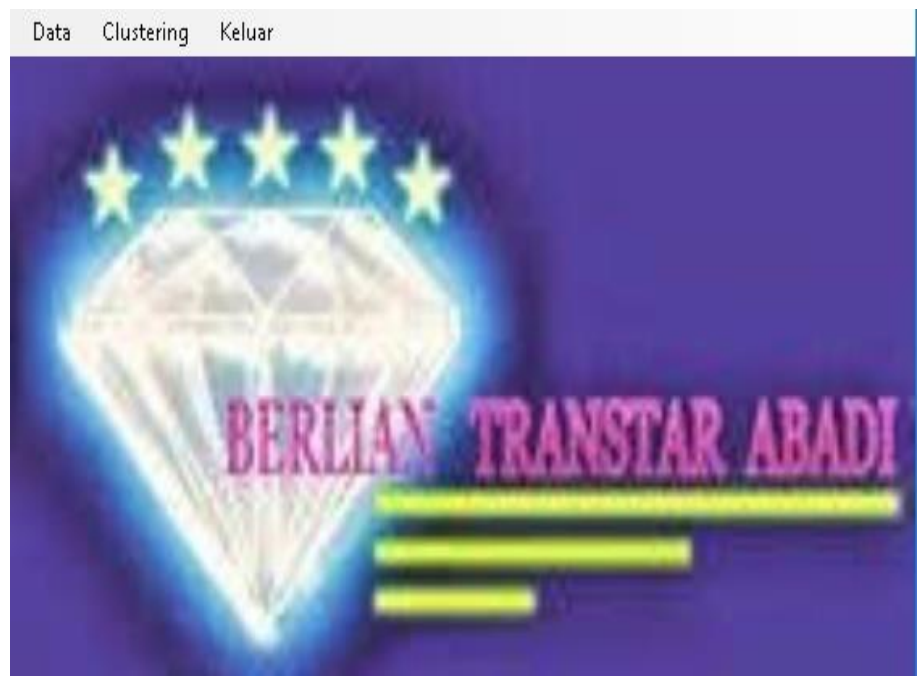

Gambar 3. Tampilan Form Main

\section{Tampilan form Data Karyawan}

Form ini digunakan untuk mengisi data karyawan yang berpotensi PHK oleh perusahaan . Data-data yang di isi dapat di simpan ke dalam 
database. Tampilan form Data Karyawan dapat dilihat pada gambar ;

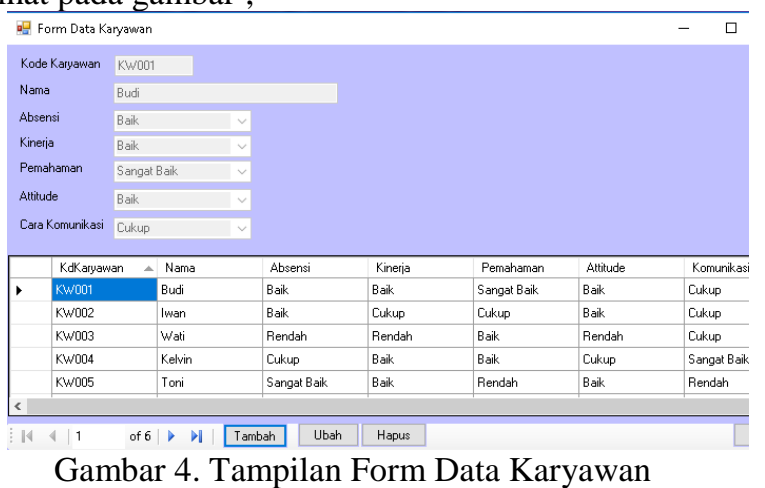

\section{Tampilan form Clustering}

Setelah selesai mengisi data karyawan yang diperlukan, maka proses dapat dilanjutkan ke proses Clustering. Adapun proses yang dilakukan mencakup:

Pengumpulan daya karyawan yang telah di input, untuk mengetahui nama-nama karyawan dan termasuk bagian cluster mana karyawan tersebut berada dilihat dari Absensi, Kinerja, Pemahaman, Attitude, Cara komunikasi. Seperti terlihat pada gambar berikut:

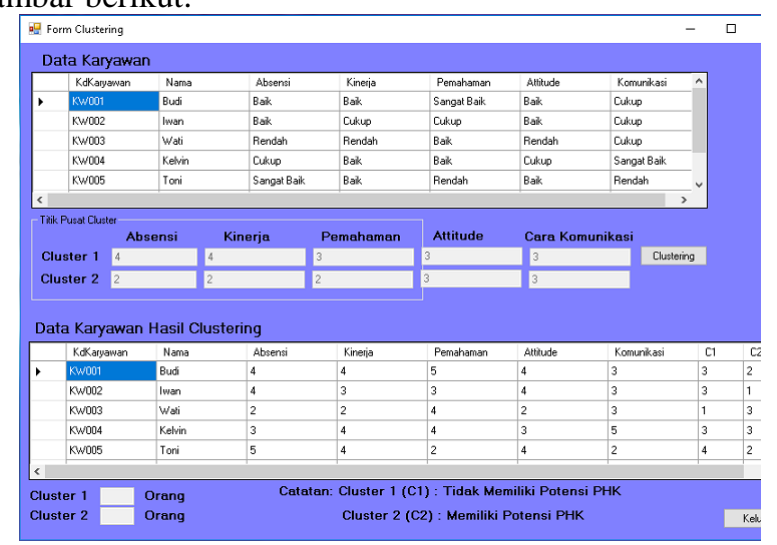

Gambar 5. Tampilan Form Clustering

\section{Tampilan Form Cluster Akhir}

Terakhir, Pemakai dapat menghitung berapa orang yang termasuk cluster 1 dan cluster 2 dengan menekan tombol cluster. Hasilnya dapat di lihat pada gambar berikut:

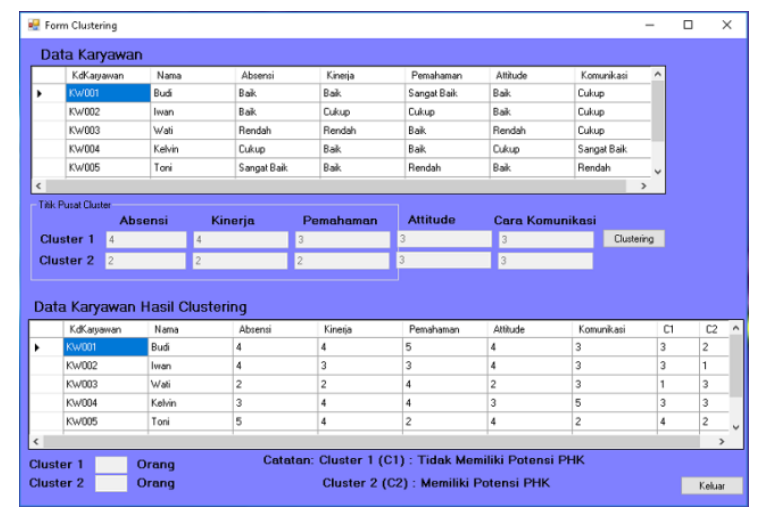

Gambar 6. Tampilan Form Cluster Akhir

\section{Kesimpulan}

Berdasarkan hasil penelitan diatas, maka peneliti menarik kesimpulan sebagai berikut :

Metode K-Mean Clustering dapat digunakan untuk melakukan pengelompokkan dan prediksi karyawan yang berpotensi PHK ke dalam 2 kelompok, yaitu memiliki potensi PHK dan tidak memiliki potensi PHK.

Implementasi Metode $K$-Mean Clustering ke dalam Data Mining cukup efektif dilakukan karena jika semakin banyak data karyawan yang diinputkan maka semakin banyak juga hasil Clustering.

\section{PENUTUP}

Peneliti memberikan saran sebagi berikut :

1.Hasil Clustering perlu dikembangkan sehingga tidak hanya membahas tentang karyawan yang berpotensi PHK, namun juga bisa mengelompokkan bonus karyawan, pemilihan karyawan terbaik, dan lain sebagainya.

2.Perlunya penggunaan metode atau algoritma Clustering lainnya untuk pengelompokkan dan prediksi, sehingga dapat diketahui algoritma mana yang paling efektif diterapkan dalam perusahaan

\section{DAFTAR PUSTAKA}

[1] Siska Haryati, Aji Sudarsono, dan Eko Suryana, "Implementasi Data Mining untuk Memprediksi Masa Studi Mahasiswa menggunakan algoritma", Jurnal Media Infotama Vol 11 No. 2, 2015

[2] Randi Rian Putra , Cendra Wadisman, "Implementasi Data Mining Pemilihan Pelanggan Potensial menggunakan Algoritma K-Means" , INTECOMS Volume 1 No 1, 2018

[3] Rony Setiawan, “ Penerapan Data Mining menggunakan Algoritma K-Means Clustering untuk Menentukan Strategi Promosi Mahasiswa Baru", Jurnal Lentera ICT Vol.3 No.1, 2016

Contac person : 